\title{
O VALOR DOS VALORES: AVALIAÇÃO DE UMA \\ MARCA GLOBAL POR MEIO DOS DIVERSOS BRASIS
}

CULTURAIS

\section{THE VALUE OF VALUES: A GLOBAL BRAND'S ASSESSMENT ACROSS BRAZILIAN CULTURAL DIVERSITY}

EDAR DA SILVA AÑAÑA

Doutor em Administração pela Escola de Administração da Universidade Federal do Rio Grande do Sul (UFRGS). Professor adjunto da Faculdade de Administração e Turismo da Universidade Federal de Pelotas (UFPel). Rua Almirante Barroso, 1.734, Centro - Pelotas - RS - Brasil - CEP 96010-280 E-mail: esanana@ea.ufrgs.br

WALTER MEUCCI NIQUE Doutorado em Administração de Estado e Ciências da Administração da Universidade Pierre Mendès - França. Professor associado do Programa de Pós-Gradução em Administração da Universidade Federal do Rio Grande do Sul (UFRGS). Rua Washington Luiz, 855, Centro - Porto Alegre - RS - Brasil - CEP 90010-460 E-mail:wmnique@ea.ufrgs.br 


\section{RESUMO}

Este trabalho explora as influências dos valores pessoais e de outros elementos da cultura brasileira, na avaliação de uma marca de alcance mundial, por meio de quatro subculturas regionais que são utilizadas como unidades de análise. Utiliza as escalas de Rokeach (1968, I973) para medir os valores humanos e a de Aaker (I997) para avaliar os atributos da marca, numa amostra de 308 pessoas, entre estudantes e profissionais de nível superior. O resultado confirma a existência de relações significativas entre os valores pessoais e a percepção da marca Nike, bem como a influência dos rituais, dos símbolos e de algumas variáveis demográficas, na forma como aquela marca é percebida e avaliada pelos consumidores. Confirma também a existência de diferenças significativas entre os elementos culturais das diversas subculturas, que podem ser bastante úteis na formulação de estratégias de marketing voltadas às diversas regiões do país.

\section{PALA VRAS-CHAVE}

Valores pessoais; Cultura; Subcultura; Marca; Percepção.

\section{ABSTRACT}

This paper explores the influences of personal values and of other cultural elements in the assessment of a global brand across four Brazilian regional subcultures. It uses the Rokeach Values Survey (1968, 1973) to measure personal values, and the Brand Personality Scale, of Aaker (1997), to interpret brand attributes in a sample 308 university students and high-schooled people. Results detected significant relationship amongst personal values and the brand evaluation, and confirmed some influence of rituals, symbols and demographics in the way consumers perceive an international brand like Nike. Personal values and other cultural elements of subcultures showed significant differences that can be useful for marketing strategies intended to the specific areas of that country. 


\section{KEYWORDS}

Personal values; Culture; Subculture; Brand; Perception.

\section{INTRODUÇ ̃̃O}

A tentativa de entender o significado e as decisões de consumo por meio dos valores pessoais não é de todo nova, mas o seu estudo ainda oferece interessantes espaços de investigação. Vários autores têm buscado, através dos tempos, aprofundar o conhecimento sobre os valores humanos, contribuindo assim para o entendimento das motivações e do significado do consumo. O interesse pelo assunto, segundo Clawson e Vinson (I978), remonta à segunda década do século $\mathrm{XX}$, quando Copeland (i924) propunha que os apelos de compra poderiam ser classificados em duas dimensões: num eixo estariam as motivações primárias (relacionadas à classe de produto), seletivas (relacionadas à escolha da marca) ou de patrocínio habitual (relacionadas à escolha da loja) e, no outro eixo, os elementos de decisão (racional ou emocional). Embora ainda sem se referir especificamente ao termo "valor", Copeland (I924), na época, já defendia que os motivos emocionais da decisão de compra teriam origem nos instintos e nas emoções humanas, como o orgulho com a aparência pessoal e a autorrealização, entre outras motivações que hoje são classificadas como valores.

O tema "valores", porém, só atingiu status de área isolada de estudo com a obra de Rokeach (1968, I973). Conforme esse autor, o valor é uma crença duradoura segundo a qual um modo específico de conduta (um valor instrumental), ou um estado final de existência (um valor terminal), é pessoal ou socialmente preferível a outro modo de conduta ou a outro estado final de existência.

Ao longo dos tempos, diversos autores têm buscado aprofundar o conhecimento relativo aos valores e à sua relação com o consumo. Autores como Schwartz e Bilsky (I987), Schwartz (I992), Schwartz e Savig (I995), Gouveia et al. (200I), Teixeira et al. (2006) e Teixeira e Domenico (2008) têm se dedicado à identificação de tipologias de valores de alcance mais ou menos universal, baseadas nas similaridades e nos antagonismos dos valores entre si. Outros, como Pitts e Woodside (1983), Kahle, Beatty e Homer (1986), Kahle e Kennedy (i988), Novak e MacEvoy (I990), Kamakura e Mazzon (I99I) e Kamakura e Novak (I992), têm empregado os valores pessoais em estudos relacionados à segmentação de mercados.

A conexão entre os valores pessoais e os atributos de produtos ou de marcas ganhou impulso com a teoria da cadeia de meios e fins (GUTMAN, I982). Desde aquele marco referencial até os dias atuais, autores como Reynolds e 
Gutman (I994), Valette-Florence e Rapacchi (I99I) e Vriens e Hofstede (2000) têm buscado entender as conexões entre os valores, as consequências (desejáveis ou indesejáveis) do consumo e os atributos dos produtos ou marcas. A lógica subjacente à teoria da cadeia de meios e fins é que os produtos possuem atributos (concretos ou abstratos), cujo consumo gera consequências (funcionais ou psicológicas), importantes para satisfazer valores (terminais ou instrumentais).

A metáfora da lente de marketing (marketing lens model) (BRISTOW, I998; BRISTOW; AMYX, 200I, AMYX; BRISTOW; SCHNEIDER, 2004) aborda a relação valores-marca de forma ainda mais direta. Para os autores dessa corrente, o nível de conhecimento, as expectativas e os valores sociais e culturais modelam a percepção dos consumidores sobre o mundo em que vivem e as coisas que compartilham. Por essa razão, os profissionais de marketing devem adaptar os produtos aos sistemas de valores das culturas que pretendem atingir.

Os valores constituem a parte mais interna e estável da cultura (VINSON; SCOTT; LAMONT, I977) e "são invisíveis até o momento em que se tornam evidentes através do comportamento" (HOFSTEDE, 200I, p. IO). Mas, além dos valores, outros "elementos visíveis da cultura", como os símbolos, os heróis e os ritos, também podem contribuir para modelar a percepção de produtos ou marcas. O presente trabalho utiliza a versão intervalar da Rokeach values survey (RVS) (ROKEACH, I968, I973), composta por I8 valores terminais e I8 valores instrumentais, colhidos por meio de questionários eletrônicos adaptados para a internet, para capturar os valores pessoais dos respondentes.

O estudo busca identificar relações entre os valores pessoais e outros fatores culturais e demográficos, e avaliar a sua influência na percepção de uma marca de alcance universal. Além da cultura, o estudo emprega ainda outros elementos, como a identidade social (TURNER, I975) e algumas variáveis demográficas (sexo, idade e escolaridade) como possíveis influenciadores da percepção. Utiliza uma marca conhecida universalmente como elemento de referência e busca entender como os diferentes filtros culturais e demográficos condicionam a percepção dos consumidores acerca daquele símbolo de consumo. A pesquisa emprega as subculturas regionais brasileiras como unidades de análise, por serem bem características e documentadas na literatura antropológica (LENARTOWICZ; ROTH, 200I), e cujos tipos regionais se diferenciam uns dos outros, pelo ambiente em que vivem, por sua história, tradições etc.

\section{CULTURA E IDENTIDADE SOCIAL}

Conforme Hofstede (200I), uma das formas mais simples de entender a cultura é por meio de sua definição antropológica. Vista por esse ângulo, a cultura é um padrão de pensar, sentir e reagir dos grupos humanos, que é adquirido e 
transmitido principalmente por símbolos representativos das ideias e dos valores grupais. A avaliação da cultura comporta duas abordagens, uma centrada na própria cultura e outra centrada na personalidade. De acordo com Clark (I990, p. 70), a abordagem centrada na cultura é essencialmente qualitativa, enquanto a abordagem centrada na personalidade permite a obtenção de medidas quantitativas, por meio da "tabulação de traços individuais" (p. 70), e isto torna a segunda abordagem mais interessante para estudos de natureza gerencial como este.

Além dos valores que somente são visíveis através do comportamento (DASGUPTA, I997), a cultura também se manifesta por meio de outros elementos, como os rituais, os heróis e os símbolos, que são visíveis nas práticas quotidianas. O ritual é um tipo de ação social na qual o significado cultural é manipulado: "É uma oportunidade para evocar, afirmar, atribuir ou revisar símbolos convencionais e significados, dentro de uma ordem cultural" (MCCRACKEN, I986, p. 78). Assim, ainda que a prática religiosa seja um tipo importante de ritual (LUNA; GUPTA, 200I), o conceito não se restringe às práticas com significado místico ou religioso. O termo ritual define o conjunto de comportamentos habituais que ocorrem durante uma atividade de caráter simbólico-expressivo, que se repete periodicamente obedecendo a uma sequência preestabelecida.

Os símbolos são representações, gestos, atitudes, comportamentos ou objetos cujo significado é compartilhado por um determinado grupo. Entre os símbolos mais estudados pelos acadêmicos de marketing, figuram a linguagem e os produtos de consumo (LUNA; GUPTA, 200I). Os valores culturais expressam a percepção da realidade, e as crenças coletivas sobre o que é certo ou errado são transferidas para os produtos por meio da publicidade (BELK, I985). E uma vez carregados de significado simbólico, os produtos acabam sendo consumidos pelos indivíduos como forma de autoexpressão. Os heróis, por sua vez, são pessoas vivas ou mortas, reais ou imaginárias, dotadas de características que são apreciadas pela coletividade e que, por isso, servem como modelo de comportamento (HOFSTEDE, 200I).

A identidade social é parte do autoconceito e se expressa pelo sentido de pertinência a um grupo social, que o indivíduo considera importante para si (TURNER, I975). Conforme Tajfel e Turner (apud BROWN, 2000), as pessoas emprenham-se em construir uma identidade social positiva como forma de aumentar a autoestima, seja comparando-se aos demais elementos do grupo, seja por comparação a outros grupos relevantes.

A cultura é um agregado de características comuns que influenciam as respostas do grupo ao seu ambiente (HOFSTEDE, 200I), e, portanto, o termo tanto pode ser aplicado a uma nação inteira como a grupos étnicos ou regionais. $\mathrm{O}$ presente trabalho utiliza os valores, a prática religiosa (um ritual) e o uso da Nike (um símbolo) para representar a cultura. 
Como as nações nem sempre são homogêneas, é compreensível que existam dentro delas grupos étnicos ou regionais com subculturas diferentes. Assim, mesmo que esses grupos compartilhem uma cultura própria de cada um deles, todos trazem alguns traços culturais que os identificam com a nação à qual pertencem. Nos Estados Unidos, por exemplo, negros, hispânicos, asiáticos e caucasianos reproduzem culturas que são características de cada grupo, porém todos são vistos como "americanos" por outros povos. O trabalho utiliza as identidades sociais associadas a algumas subculturas regionais brasileiras como unidade de análise, para avaliar possíveis diferenças entre elas, que permitam melhor entender a forma como enxergam um objeto de consumo, representado por uma marca de alcance universal.

Conforme Lenartowicz e Roth (200I), as subculturas são subdivisões da cultura nacional, compostas por uma combinação de situações, como classe social, etnia, região de residência ou filiação religiosa que, juntas, formam uma unidade funcional. Dessa forma, "as subculturas podem ser baseadas no compartilhamento de aspectos históricos ou geográficos, que tenham influenciado os valores do grupo" (LENARTOWICZ; ROTH, 200I, p. 308). No caso presente, os grupos utilizados como unidade de análise podem ser tratados como subculturas regionais (MUZZIO; CASTRO, 2008), já que a identidade social dos respondentes foi apanhada por declaração. Como o país viveu diversos processos migratórios internos, não são raros os grupos de "nordestinos" ou de "gaúchos" que vivem e cultuam as suas tradições em diversas partes do país. Assim, o tipo regional que está sendo utilizado se baseia no compartilhamento de valores e de comportamentos próprios de cada subcultura, mas não significa que os respondentes sejam residentes (ou que tenham nascido) nas regiões com as quais se identificam.

\section{OS VALORES HUMANOS}

Os valores constituem uma das formas mais abstratas de conhecimento individual. Logo, a associação de um produto, serviço ou ideia a um valor abstrato facilita sobremaneira a sua memorização e recuperação (KAHLE; KENNEDY, I988). Os valores, segundo Rokeach (I968, I973), têm a ver com os modos de conduta e os estados finais da existência, e, uma vez internalizados, passam a ser critério para guiar as ações e para desenvolver e manter as atitudes em relação a objetos e situações relevantes.

Valores são crenças ou metas transituacionais que as pessoas usam para armazenar e guiar suas respostas em direção a uma determinada classe de estímulos. Valores são referências que as pessoas utilizam para julgar a si ou aos outros (NIQUE; ESPINOZA; SILVA, 2003), ou mesmo para influenciar os valores, as 
atitudes e as ações de outras pessoas (VINSON; SCOTT; LAMONT, I977). Embora existam várias definições para o termo valor, praticamente todas elas reúnem algumas características comuns: valores são a) conceitos ou crenças, b) acerca de comportamentos ou estados finais desejáveis, c) que transcendem às situações específicas, d) guiam a seleção ou a avaliação de comportamentos e eventos, e e) respeitam uma ordem de importância (SCHWARTZ; BILSKY, I987).

Uma discussão sempre presente em trabalhos que envolvem análise dos valores humanos diz respeito ao procedimento utilizado na sua mensuração. Alguns autores, como Rokeach (I973) e Kamakura e Mazzon (I99I), entendem que as escalas ordinais são mais apropriadas para medir os valores, por simularem com maior fidelidade as escolhas, quase sempre ipsativas, que as pessoas precisam fazer durante a vida. Segundo esses autores, as escalas intervalares não são adequadas para medir os valores, por permitirem o viés do "empilhamento" das respostas nas alternativas mais altas (end-piling bias). Outros, porém, como Clawson e Vinson (I978), Schwartz e Bilsky (I987) e Kahle e Kennedy (I988), entendem que as escalas ordinais são limitadas em termos analíticos e difíceis de ser implementadas em termos práticos, e que as escalas intervalares podem substituir convenientemente os procedimentos ordinais. O presente trabalho utiliza uma escala intervalar de cinco pontos adaptada para a internet e ancorada nas extremidades pelos valores avaliados como mais e menos importantes, procedimento este que permite utilizar toda a riqueza analítica das escalas intervalares, com menor viés de end-piling (MCCARTY; SHRUM, 2000).

\section{A cadeIA de meIOS e fins e A LeNTE DE MARKETING}

A teoria da cadeia de meios e fins, iniciada com o trabalho de Gutman (I982), parte do pressuposto de que os valores definem estados finais desejáveis de existência e que, por isso, desempenham um papel dominante nas escolhas. Os produtos, nesse caso, são os meios utilizados pelos seres humanos para atingir o estado final desejado (valor). Como o consumo gera consequências - positivas ou negativas -, a escolha do produto para atender a determinado valor depende tanto do tipo de valor a ser atendido quanto da situação e dos atributos do produto em si, mas depende fundamentalmente do trade-off entre as consequências positivas e negativas do consumo. Como as pessoas têm à sua disposição uma grande diversidade de produtos capazes de satisfazer os seus valores, o agrupamento desses produtos em classes ou marcas (conjunto evocado) visa facilitar o processo de escolha. 
A cadeia de meios e fins apresentada por Gutman (I982) representa a conexão entre os atributos existentes nos produtos, as consequências do consumo e os valores pessoais dos consumidores. Entretanto, os atributos podem se ligar aos valores de diferentes formas. Segundo Overby, Gardial e Woodruff (2004), é possível que, numa situação de consumo, um consumidor perceba a ligação entre um atributo específico, uma consequência e um estado final, e outro consumidor perceba múltiplas conexões entre alguns atributos, algumas consequências e alguns estados finais. Também é possível que as conexões sejam interpretadas tanto de cima para baixo quanto de baixo para cima, ou seja: numa conexão do tipo top-down em que o estado final (valor) a ser atendido determina a importância que tem cada consequência de consumo, e numa conexão bottom-up em que o consumidor aprende, com o uso, a reconhecer as consequências (desejáveis ou indesejáveis) de cada atributo do produto.

Outra abordagem interessante para o entendimento da relação entre os valores pessoais e a marca envolve a utilização do marketing lens model, uma metáfora cujas origens remontam ao trabalho de Brunswik (I952) (cf. BRISTOW, I998). A "lente de marketing" tem sido utilizada como base teórica para a análise de perspectivas de diferentes grupos sociais. Bristow e Amyx (200I), por exemplo, utilizam o marketing lens model para comparar os valores de estudantes de origem indígena (Navajos) com os dos brancos, de origem anglicana. O modelo presume que as experiências, os diferentes níveis de conhecimento, as expectativas e os valores sociais e culturais modelam a percepção dos consumidores sobre o mundo que eles compartilham. Entre os trabalhos que utilizam a "lente de marketing" para explicar a percepção por meio dos valores dos respondentes, encontram-se os de Bristow (I998) e de Bristow e Amyx (200I) que utilizam o modelo para comparar as percepções dos estudantes e dos dirigentes educacionais sobre os atributos dos produtos educacionais (sic). Outros utilizam o modelo para analisar a influência das diferenças culturais de consumidores navajos e anglicanos, na lealdade à marca e na alienação em relação à publicidade (AMYX; BRISTOW; SCHNEIDER, 2004).

\section{A PERSONALIdAdE DA MARCA E SUA RELAÇÃO COM OS VALORES}

Conforme a American Marketing Association (AMA), uma marca pode ser um nome, termo, sinal, símbolo ou desenho, ou mesmo uma combinação destes, que se destina a identificar os bens ou serviços oferecidos por um vendedor ou grupo de vendedores, e a diferenciá-los dos concorrentes. Essa definição tem sido criticada por ser um tanto mecânica e por enfatizar excessivamente os 
atributos físicos do produto. Conforme Chernatony e Riley (I997), a marca é uma conexão entre as atividades de marketing da empresa e as percepções dos consumidores acerca dos seus elementos funcionais e emocionais. Portanto, "a perspectiva da AMA, que apresenta a marca como logos, já não se presta aos dias atuais" (CHERNATONY; RILEY, I997, p. 69).

Pesquisas têm demonstrado que "marca" é um conceito multifacetado e que nem todas as suas facetas são facilmente percebidas pelos consumidores. A marca é um complexo de valor que a empresa se propõe a entregar e que, portanto, não se resume a um logo ou a um símbolo. A marca é o resultado de um processo contínuo e coordenado de atividades organizacionais, que são interpretadas e internalizadas pelos consumidores. Uma metáfora interessante para o entendimento do real significado de marca é a do "iceberg de marca". A parte visível do iceberg (aproximadamente $15 \%$ do tamanho) corresponde ao logo e ao nome da marca; o restante representa valores, intelecto e cultura (CHERNATONY, 2006).

Outro conceito por meio do qual se pode entender, analisar e até mesmo medir os atributos de uma marca é o de personalidade da marca. As pessoas geralmente não têm dificuldade em atribuir qualidades pessoais a objetos inanimados (AAKER, I997), em pensar sobre marcas como se elas possuíssem traços humanos e em animar produtos com os quais se relacionam. A vitalidade pode ser percebida na marca por meio de diferentes formas de animismo. A imagem da marca pode ser associada a uma pessoa próxima (por exemplo, uma avó) ou distante (por exemplo, uma celebridade), cuja lembrança é evocada através dela. A marca, nesse caso, funciona como uma entidade animada que, de alguma maneira, incorpora parte do espírito da pessoa endossante (FOURNIER, I998). Mas a marca também pode ser antropomorfizada diretamente no imaginário das pessoas, que passam a perceber nela algumas qualidades humanas como emoção, intelecto e volubilidade. "Os valores emocionais de uma marca são também inferidos a partir do seu desenho, embalagem e outros sinais emitidos pelo vendedor, como o preço e a apresentação no ponto de venda" (CHERNATONY, 2006, p. 40).

A personalidade da marca também pode atuar como símbolo de autoexpressão. As pessoas não compram um carro de determinada marca simplesmente pela performance que a marca garante, mas também por aquilo que ela representa em termos de status ou de estilo de vida. Na medida em que as pessoas convivem em sociedade, as marcas por elas utilizadas adquirem significado simbólico, e os consumidores valem-se da personalidade da marca para projetar os seus próprios traços de personalidade ou expressar seu autoconceito. Como forma de aumentar a autossatisfação, os indivíduos tendem a se aproximar daqueles produtos cujas personalidades sejam congruentes com o seu ideal de autoimagem 
e a se afastar dos produtos cujas personalidades sejam percebidas como discrepantes em relação àquela que desejam ter (CHANG, 2002). O presente trabalho utiliza a brand personality scale (BPS) (AAKER, I997), composta por 42 atributos, para capturar a intensidade com que cada atributo é percebido na Nike.

\section{MODELO TEÓRICO}

O trabalho, de cunho exploratório-descritivo, parte do pressuposto de que os valores, por serem o componente mais íntimo e estável da cultura, podem influenciar outros elementos mais periféricos como os rituais, os heróis e os símbolos, e também ser reforçados por tais práticas. Assume também que a percepção das pessoas acerca de uma marca pode ser influenciada tanto pelos valores pessoais daqueles(as) que a avaliam quanto pelos filtros que se interpõem entre os valores e a marca propriamente dita. E entre os possíveis filtros modeladores da percepção, encontram-se os elementos culturais e a identidade social ou grupal, além das variáveis demográficas.

Por tratar-se de uma prática ritualística, a religião interage com os valores (HOFSTEDE, 200I) e influencia o comportamento do consumidor, seja na resistência às mudanças (SPECK; ROY, 2008), seja na mediação direta da comunicação das marcas (MICHELL; AL-MOSSAWI, I999). Dessa forma é possível hipotetizar que:

- H-I: A prática religiosa interage com os valores e influencia o uso/não uso e a avaliação de uma marca simbólica como a Nike.

A idade é um componente importante na formação/reforço/modificação dos valores dos consumidores. Conforme Schwartz (2006), na medida em que envelhecem, as pessoas tendem a se envolver mais em atividades sociais e a ser mais comedidas e menos propensas à excitação e aos desafios. Isso permite hipotetizar que:

- H-2: A idade correlaciona-se positivamente com os valores relacionados à segurança, à tradição e à conformidade, e negativamente com a estimulação, o hedonismo e com os desafios da autorrealização.

As pessoas com maior escolaridade valorizam mais a autodeterminação e a estimulação, e são menos conformistas e tradicionais (SCHWARTZ, 2006), sendo, portanto, possível hipotetizar que: 
- H-3: O nível de escolaridade dos respondentes correlaciona-se positivamente com a autodeterminação e a abertura às mudanças, e negativamente com o conservadorismo.

Estudiosos das diferenças de gênero têm proposto que os homens sejam mais assertivos, confiantes e ambiciosos (angentic-instrumental), e que as mulheres sejam mais sensíveis, conciliadoras e afetuosas (expressive-communal). Conforme Schwartz e Rubel (2005), os homens dão maior importância ao poder, à estimulação, ao hedonismo, à realização e à autodeterminação do que as mulheres. Portanto, espera-se que:

- H-4: Os brasileiros do sexo masculino sejam mais assertivos e ambiciosos, e que as mulheres sejam mais conciliadoras e transcendentes.

Como as nações nem sempre são homogêneas, é compreensível que existam dentro delas alguns grupos étnicos ou regionais com subculturas diferentes. A homogeneidade da cultura nacional varia de uma sociedade a outra, podendo inclusive ser muito pequena em algumas nações (HOFSTEDE, 200I). A região cultural é um espaço territorial, não necessariamente idêntico às fronteiras oficiais, onde os traços culturais, tais como valores, atitudes e comportamento de seus membros, são reconhecidamente homogêneos entre si e heterogêneos em relação a outras regiões (MUZZIO; CASTRO, 2008).

Conforme Lenartowicz e Roth (200I), subculturas são subdivisões da cultura nacional, compostas por uma combinação de situações sociais como classe social, etnia, região de residência ou filiação religiosa que, juntas, formam uma unidade. No caso brasileiro, por causa das migrações internas, é comum encontrar grupos de "nordestinos" ou de "gaúchos" vivendo e cultuando suas tradições em diversas partes do país. Assim, os tipos regionais brasileiros não correspondem, necessariamente, à área de residência ou de nascimento dos respondentes. Como todos falam uma mesma língua e compartilham um corpo comum de tradições, cujo significado é mais forte do que qualquer variante subcultural (HILAL, 2006), espera-se que:

- H-5a: Existam diferenças significativas nos valores dos brasileiros, conforme a subcultura regional com a qual se identificam.

- H-5b: A unidade cultural brasileira prevaleça sobre as diversas subculturas regionais.

O marketing lens model (BRISTOW, I998; BRISTOW; AMYX, 200I; AMYX; BRISTOW; SCHNEIDER, 2004) assume que, entre outros fatores, as experiên- 
cias, as expectativas e os valores sociais e culturais modelam a percepção dos consumidores sobre o mundo que eles compartilham. Logo, é possível hipotetizar que:

- H-6: Os valores (terminais e instrumentais) dos brasileiros influenciam a percepção dos respondentes acerca de uma marca mundialmente conhecida.

Reynolds e Gutman (200I) referem-se a uma hierarquia nos níveis de abstração, determinada pela cadeia de meios e fins, segundo a qual os valores terminais representam o mais alto nível de abstração, seguidos dos valores instrumentais e das consequências do consumo. E no ponto mais baixo da escala, já no nível do concreto, estariam as características (abstratas e físicas) do produto. Por isso, é possível hipotetizar que:

- H-7: A posse/uso de uma marca simbólica interage com os valores e medeia a relação entre estes e a percepção da marca propriamente dita.

\section{MÉTODO}

O trabalho utiliza uma amostra de 308 respondentes, entre acadêmicos e profissionais de nível superior, de quatro diferentes regiões brasileiras, que avaliaram a marca por meio da BPS. Os questionários, colhidos pela internet, continham as 36 variáveis da RVS, mais as 42 variáveis da BPS, além de questões demográficas e de outras referentes à prática religiosa, ao uso da marca e à identidade social. A RVS foi escolhida para a mensuração dos valores para facilitar comparações e análises posteriores (SCHWARTZ; BILSKY, I987) e por ser largamente utilizada em pesquisas de marketing, inclusive no contexto brasileiro (NIQUE; ESPINOZA; SILVA, 2003). A BPS, aqui utilizada para aferir a percepção dos respondentes sobre a marca, também é frequentemente utilizada em pesquisas de marketing, entre outras razões, por sua adequação para mensurar os significados simbólicos da marca (AUSTIN; SIGUAW; MATTILA, 2003).

Afora a RVS e a BPS adaptadas para a internet, o questionário continha ainda questões dicotômicas referentes à prática religiosa (um ritual), ao uso ou não uso da marca Nike (um símbolo), além de outras questões demográficas. A identificação regional utilizou duas das subculturas empregadas por Lenartowicz e Roth (200I) - gaúcha e mineira - e acrescentou mais duas por conveniência: a nordestina e a sulista não gaúcha.

O tipo aqui tratado genericamente como "nordestino" representa tanto os descendentes da "cultura crioula, centrada na família patriarcal da casa-grande 
e da senzala" quanto a "fração interiorana, que se desenvolveu na aridez das caatingas e deu origem ao cabeça-chata nordestino" (RIBEIRO, I995, p. 97). E o sulista (não gaúcho) identifica-se basicamente com os hábitos e costumes do Paraná e de Santa Catarina, tendo em vista que o regionalismo sulino não abrange a região como um todo. Conforme Da Mata (2003, p. 28), ao contrário do que ocorre no Norte, onde os hábitos e costumes são mais ou menos abrangentes, "aqui não se pode confundir o Rio Grande com Santa Catarina e muito menos com o Paraná”.

O recorte regional foi estabelecido por afinidade declarada a um tipo regional característico de uma subcultura, tendo em vista que a coleta de dados foi feita por resposta, e não por observação. Conforme Lenartowicz e Roth (I999, p. 784), o uso da afiliação regional como proxy da cultura é admissível "desde que os respondentes possam ser questionados sobre o local onde passaram a infância, época na qual ocorre a sedimentação dos valores". No caso presente, mais do que o local de infância, os respondentes foram solicitados a escolher, entre diversas opções, o "tipo regional que melhor representa o seu jeito de ser e de agir", o que implicitamente inclui os valores predominantes nas diversas regiões.

Como o objetivo maior do trabalho era investigar possíveis influências dos valores e de outros construtos na percepção de uma marca, as relações entre os construtos foram analisadas em duas etapas, conforme sugerem Anderson e Gerbing (I988) e Kline (I998). Na primeira etapa, os modelos de mensuração de ambas as escalas foram estimados por meio de análise fatorial exploratória/confirmatória (E/CFA), e, após isso, o modelo estrutural foi estimado com análise de caminhos. A E/CFA foi escolhida para estimação do modelo de mensuração, por ser uma importante precursora da análise fatorial confirmatória, que "permite ao pesquisador explorar melhor a estrutura de relações antes de passar a uma abordagem confirmatória" (BROWN, 2006, p. I93). Ela representa um passo intermediário entre a EFA e a CFA, e oferece importantes subsídios para a definição da estrutura de relações quando ainda não existe suporte teórico suficiente para testar um modelo confirmatório.

\section{RESULTADOS}

A análise preliminar da amostra demonstra que a distribuição dos respondentes não é uniforme entre as subculturas. A distribuição de frequências por subcultura regional revela a existência de diferenças significativas no tamanho dos grupos $\left(\chi^{2}=262 ; G L=3 ; P=0,00\right)$, com clara predominância dos gaúchos (200 elementos) sobre os demais. Não há diferença significativa de gênero $\left(\chi^{2}=3\right.$,I24; 
$\mathrm{GL}=6 ; \mathrm{P}=0,793)$ ou na frequência de uso da marca $\left(\chi^{2}=\mathrm{I}, \mathrm{I} 4 ; \mathrm{GL}=3 ; \mathrm{P}=0,767\right)$, entre os diversos segmentos regionais. Ainda que nordestinos e sulistas (não gaúchos) sejam mais propensos à prática religiosa que gaúchos e mineiros, as diferenças não chegam a ser significantes no nível de 5\%, conforme se vê na Tabela I.

\section{TABELA I}

DISTRIBUIÇÃO DA AMOSTRA POR GÊNERO, RELIGIOSIDADE E USO DA NIKE, ATRAVÉS DAS SUBCULTURAS

\begin{tabular}{|c|c|c|c|c|c|c|c|c|}
\hline \multirow{2}{*}{ SUBCULTURA } & \multicolumn{3}{|c|}{ GÊNERO } & \multicolumn{2}{|c|}{ RELIGIÃO } & \multicolumn{2}{|c|}{ USUÁRIO DA NIKE } & \multirow{2}{*}{ TOTAL } \\
\hline & MASC. & FEM. & $\begin{array}{l}\text { NÃO } \\
\text { RESP. }\end{array}$ & NÃO & SIM & NÃO & SIM & \\
\hline \multirow{2}{*}{ Mineiro } & 15 & 18 & 1 & 26 & 8 & 8 & 26 & 34 \\
\hline & $44,1 \%$ & $52,9 \%$ & $2,9 \%$ & $76,5 \%$ & $23,5 \%$ & $23,5 \%$ & $76,5 \%$ & $100 \%$ \\
\hline \multirow{2}{*}{ Gaúcho } & 83 & 113 & 4 & 154 & 46 & 55 & 145 & 200 \\
\hline & $41,5 \%$ & $56,5 \%$ & $2,0 \%$ & $77,0 \%$ & $23,0 \%$ & $27,5 \%$ & $72,5 \%$ & $100 \%$ \\
\hline \multirow{2}{*}{ Sulista } & 17 & 16 & 0 & 22 & 11 & 9 & 24 & 33 \\
\hline & $51,5 \%$ & $48,5 \%$ & $0,0 \%$ & $66,7 \%$ & $33,3 \%$ & $27,3 \%$ & $72,7 \%$ & $100 \%$ \\
\hline \multirow{2}{*}{ Nordestino } & 20 & 21 & 0 & 24 & 17 & 14 & 27 & 41 \\
\hline & $48,8 \%$ & $51,2 \%$ & $0,0 \%$ & $58,5 \%$ & $41,5 \%$ & $34,1 \%$ & $65,9 \%$ & $100 \%$ \\
\hline Total & 135 & 168 & 5 & 226 & 82 & 86 & 222 & 308 \\
\hline$\%$ & $43,8 \%$ & $54,5 \%$ & $1,6 \%$ & $73,4 \%$ & $26,6 \%$ & $27,9 \%$ & $72,1 \%$ & $100 \%$ \\
\hline$\chi^{2}$ (G. L.) & \multicolumn{3}{|c|}{$3,124(6)$} & \multicolumn{2}{|c|}{$6,893(3)$} & \multicolumn{2}{|c|}{$1,140(3)$} & - \\
\hline Sig. & \multicolumn{3}{|c|}{0,793} & \multicolumn{2}{|c|}{0,075} & \multicolumn{2}{|c|}{0,767} & - \\
\hline
\end{tabular}

Fonte: Elaborada pelos autores.

\subsection{OS MODELOS DE MENSURAÇÃO}

Os itens de ambas as escalas foram inicialmente agrupados por meio de análises fatoriais exploratórias (de uma e de outra), para estimação dos fatores que seriam utilizados como variáveis substitutas. As variáveis incluídas no modelo e o número de fatores foram identificados com base nos critérios estabelecidos por Costello e Osborne (2005): fatores com capacidade de explicar mais de 50\% da 
variância e fatores compostos por três variáveis ou mais, com eigenvalue $\geq \mathrm{I}$, alfas de Cronbach $\geq 0,7$ e cargas fatoriais $\geq 0,35$.

Foram identificadas seis dimensões na escala de valores (RVS) e cinco na escala de personalidade da marca (BPS). As dimensões da RVS agrupam valores I. de um mundo ideal (igualdade, mundo de paz, segurança familiar, segurança nacional, liberdade e salvação); 2. da realização pessoal (autorrespeito, sabedoria, harmonia interior, amizade verdadeira, autorrealização, amor maduro e reconhecimento social); 3 . de uma vida prazerosa (prazer, vida excitante e felicidade); 4. da conformidade (ser polido, responsável, autocontrolado, obediente, honesto e asseado); 5. da transcendência (ser prestativo, tolerante e amoroso); e 6. da virtuosidade (ser independente, capaz, intelectual, corajoso, imaginativo, lógico e ambicioso). As três primeiras dimensões da RVS (mundo ideal, realização pessoal e vida prazerosa) são formadas por valores terminais, e as três últimas (conformidade, transcendência e virtuosidade) por valores instrumentais.

Após a identificação dos fatores representativos dos valores pessoais, estes foram submetidos à análise confirmatória para verificação da validade convergente e discriminante. Nessa etapa, assumiu-se que cada variável deveria ter carga diferente de zero no fator que estava destinada a medir, e igual a zero em todos os demais fatores. Para efeito de identificação da escala, a variável de carga fatorial mais alta foi fixada em um $(\mathrm{I}, \mathrm{O})$ para ancorar cada fator, e os demais parâmetros foram liberados (BROWN, 2006, p. 62). O resultado confirmou que tanto a confiabilidade composta dos fatores $(>0,87)$ quanto a variância extraída $(>0,76)$ superam com folga os mínimos de 0,7 e 0,5, respectivamente, e que o valor do $\chi^{2}$ /gl é bem inferior a 5 (HAIR JUNIOR et al., I998). A validade convergente do modelo foi confirmada pela divisão das cargas fatoriais pelos erros padrão correspondentes $(>2)$, e a validade discriminante foi avaliada pelo teste de diferença de qui-quadrado, após restrição do modelo para que tivesse correlações entre os fatores iguais a I,O (ANDERSON; GERBING, I988). Embora o RMSEA igual a 0,069 encontre-se dentro do limite de aceitação, a baixa relação entre o número de casos por parâmetro estimado (< 5:I) (BAUMGARTNER; HOMBURG, I996) e os valores relativamente baixos de CFI e TLI (inferiores a o,9) sugerem necessidade de agregação dos indicadores em parcelas representativas (MACCALLUM; AUSTIN, 2000). As médias, os desvios padrão, a confiabilidade composta e a variância extraída dos fatores representativos dos valores encontram-se na Tabela 2; os indicadores e as cargas fatoriais correspondentes estão disponíveis com o primeiro autor. 
TABELA 2

DIMENSÖES REPRESENTATIVAS DOS VALORES PESSOAIS (RVS)

\begin{tabular}{lcccc}
\hline DIMENSÕES & MÉDIAS & DESVIOS PADRÃO & $\begin{array}{c}\text { CONFIABILIDADE } \\
\text { COMPOSTA }\end{array}$ & $\begin{array}{c}\text { VARIÂNCIA } \\
\text { EXTRAÍDA }\end{array}$ \\
\hline Mundo ideal & 3,83 & 0,77 & 0,905 & 0,821 \\
\hline Realização pessoal & 4,15 & 0,65 & 0,935 & 0,86 \\
\hline Prazer & 3,66 & 0,92 & 0,869 & 0,768 \\
\hline Conformidade & 3,63 & 0,75 & 0,904 & 0,811 \\
\hline Transcendência & 3,78 & 0,85 & 0,923 & 0,810 \\
\hline Virtuosidade & 3,63 & 0,74 & 0,901 & 0,814 \\
\hline
\end{tabular}

Fonte: Elaborada pelos autores.

A análise da variância dos valores humanos aponta a existência de diferenças significativas entre as subculturas, nos valores correspondentes ao mundo ideal, à realização pessoal, à conformidade, à transcendência e à virtuosidade. $\mathrm{O}$ teste LSD, de comparações múltiplas, confirma que os mineiros são significativamente menos idealistas e menos interessados na realização pessoal do que os gaúchos, os sulistas e os nordestinos. Confirma também que os sulistas (não gaúchos) valorizam mais as virtudes pessoais que os mineiros $(\mathrm{P}=0,049)$ e nordestinos $(\mathrm{P}=0,03 \mathrm{I})$. E confirma ainda que os nordestinos são significativamente mais conformistas que os mineiros $(\mathrm{P}=0, \mathrm{OI} 6)$ e mais transcendentes que os mineiros $(\mathrm{P}=0,025)$ e gaúchos $(\mathrm{P}=0,040)$. As médias dos fatores representativos dos valores pessoais encontram-se na Figura I.

\section{FIGURA I}

\section{MÉDIAS DOS VALORES PESSOAIS ATRAVÉS}

\section{DAS SUBCULTURAS REGIONAIS}

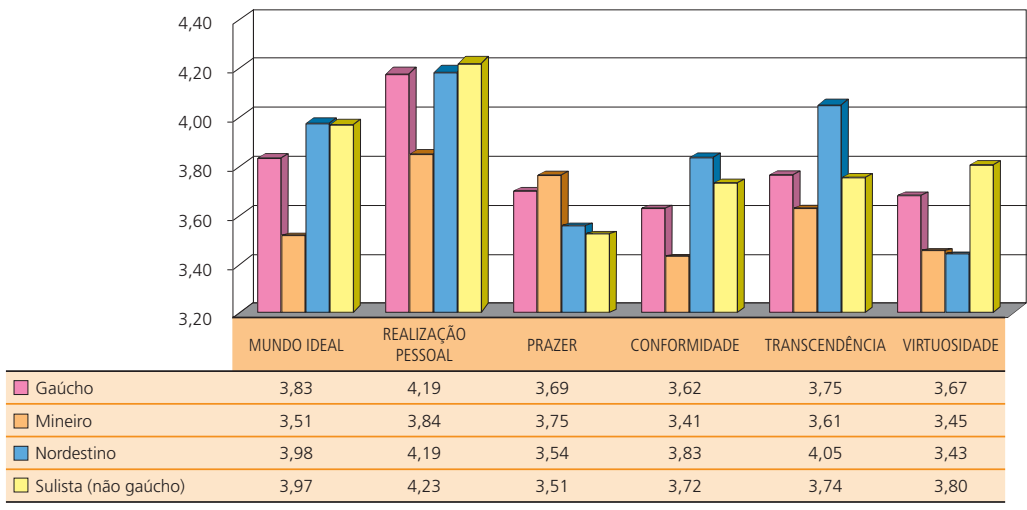

Fonte: Elaborada pelos autores. 
A análise de proximidades entre as correlações dos fatores latentes demonstra que os valores alinham-se em dois eixos relativamente ortogonais: um deles composto por valores terminais e o outro por valores instrumentais. Ambos os eixos sugerem a existência de algum antagonismo entre os interesses coletivos e individuais. No eixo dos valores terminais, os valores do mundo ideal (paz, igualdade, segurança etc.), que sugerem preocupação com o interesse da coletividade, contrastam com os do prazer e da excitação, que servem a interesses tipicamente individuais. E entre os dois extremos, conforme se vê na Figura 2, encontram-se os valores da realização pessoal (amor, amizade, autorrealização etc.) que envolvem troca de afeto e, dessa forma, servem tanto aos interesses pessoais quanto aos de pessoas próximas.

\section{FIGURA 2}

\section{CORRELAÇÕES ENTRE AS DIMENSÕES DA ESCALA DE VALORES}

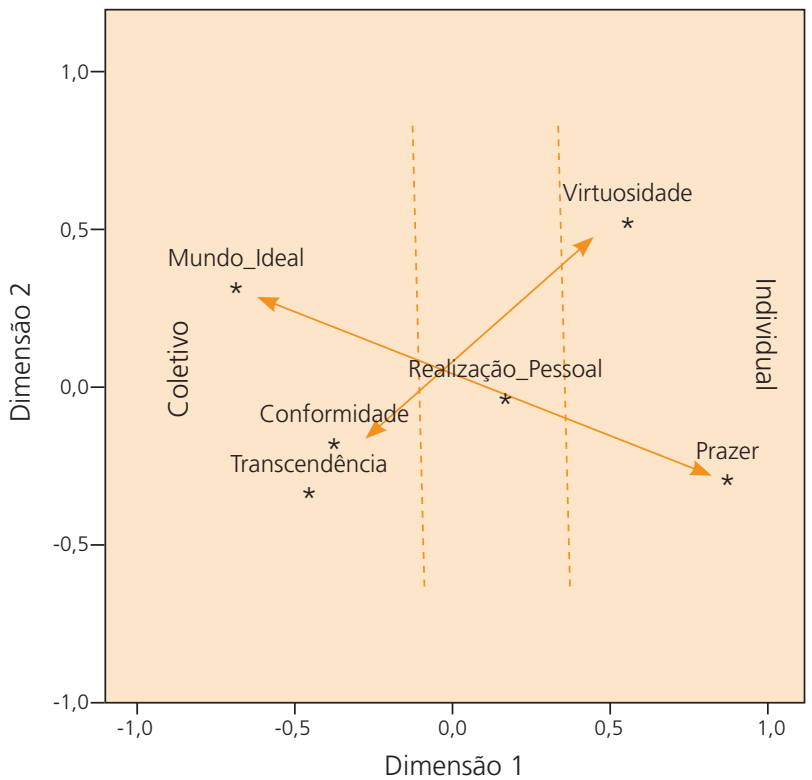

Fonte: Elaborada pelos autores.

No eixo dos valores instrumentais, percebe-se que os valores da conformidade (responsabilidade, obediência, honestidade etc.) correlacionam-se fortemente com os da transcendência (ser prestativo, tolerante, amoroso etc.) e são relativamente antagônicos às virtudes pessoais, que sugerem independência, ambição e arrojo. Assim como no caso dos valores terminais, também aqui fica evidente o contraste de interesses: a conformidade e a transcendência, por implicarem comedimento e constrição, sugerem renúncia aos próprios interesses em favor de outras pessoas; e as virtudes, ao contrário, sugerem coragem, ambição e capacidade para enfrentar os desafios individuais. 
Os cinco fatores identificados na BPS correspondem às dimensões identificadas na escala original, entretanto I3 das 42 variáveis originais não se adequaram à amostra. As dimensões identificadas na marca sugerem I. sinceridade (confiável, segura, sincera, honesta, trabalhadora, realista, sólida e saudável); 2. competência (autêntica, atualizada, vitoriosa, contemporânea, inteligente, confiante, técnica, líder, jovem e independente); 3. excitação (espirituosa, excitante, imaginativa, audaciosa e alegre); 4. rusticidade (corajosa, robusta e original); e 5. sofisticação (sedutora, fascinante e bela).

A validade convergente e discriminante foi confirmada pelos mesmos critérios aplicados à RVS, e os índices de ajustamento do resultado foram considerados satisfatórios. As médias, os desvios padrão e os índices de confiabilidade composta e de variância extraída dos fatores encontram-se na Tabela 3; os indicadores e as cargas fatoriais correspondentes estão disponíveis com o primeiro autor.

\section{TABELA 3}

DIMENSOES REPRESENTATIVAS DA PERSONALIDADE DA MARCA (BPS)

\begin{tabular}{lcccc}
\hline DIMENSÕES & MÉDIAS & DESVIOS PADRÃO & $\begin{array}{c}\text { CONFIABILIDADE } \\
\text { COMPOSTA }\end{array}$ & $\begin{array}{c}\text { VARIÂNCIA } \\
\text { EXTRAÍDA }\end{array}$ \\
\hline Sinceridade & 3,42 & 0,73 & 0,969 & 0,916 \\
\hline Competência & 4,25 & 0,60 & 0,978 & 0,936 \\
\hline Excitação & 4,03 & 0,72 & 0,964 & 0,892 \\
\hline Rusticidade & 3,83 & 0,70 & 0,853 & 0,709 \\
\hline Sofisticação & 3,64 & 0,94 & 0,984 & 0,919 \\
\hline
\end{tabular}

Fonte: Elaborada pelos autores.

Após a estimação e validação dos modelos de mensuração de ambas as escalas, os fatores identificados foram transformados em variáveis manifestas, pela média das variáveis originais presentes em cada um deles (escalas somadas) (ANDERSON; GERBING, I988), para construção do modelo estrutural que será visto a seguir.

\subsection{ESTIMAÇÃO DO MODELO ESTRUTURAL}

O modelo estrutural explorou todas as possíveis relações de dependência abordadas no modelo teórico, conforme será visto a seguir. Como nem todas 
as variáveis atendiam ao pressuposto da normalidade, o estimador robusto de máxima verossimilhança (MLM) foi utilizado em substituição ao ML convencional, por apresentar maior aptidão para lidar com dados daquele tipo (CURRAN; WEST; FINCH, I996). O MLM, "também chamado qui-quadrado de SatorraBentler" (MUTHÉN; MUTHÉN, 2007, p. 484), "estima os mesmos parâmetros do ML convencional, e ainda corrige o qui-quadrado para a não normalidade dos dados" (BROWN, 2006, p. 76). Os índices de ajustamento do modelo $\left(\chi^{2}=\right.$ 52,66; $\mathrm{GL}=44 ; \mathrm{P}=0, \mathrm{I74} ; \mathrm{CFI}=0,99 ; \mathrm{TLI}=0,98 \mathrm{I} ; \mathrm{RMSEA}=0,025 ; \mathrm{SRMR}=$ $0,043)$ foram bastante satisfatórios.

As relações nas quais a prática religiosa $(\mathrm{S} / \mathrm{N})$ e o uso/não uso da marca figuram como variáveis dependentes foram estimadas à parte com o estimador robusto de mínimos quadrados ponderados (WLSMV) (MUTHÉN; MUTHÉN, 2007), disponível no pacote M-Plus, por ser "a melhor opção atualmente disponível para a estimação de dados categóricos" (BROWN, 2006, p. 388). O ajustamento da estimação foi igualmente satisfatório: $\chi^{2}=0,730 ; \mathrm{GL}=\mathrm{I} ; \mathrm{P}=0,3927$; $\mathrm{CFI}=\mathrm{I} ; \mathrm{TLI}=\mathrm{I}, \mathrm{I} 6 \mathrm{I} ; \mathrm{RMSEA}=0,00 ; \mathrm{WRMR}=0, \mathrm{I} 78$.

A Figura 3 retrata, de forma simplificada, as relações significantes do modelo estrutural. Algumas relações, como [mundo ideal $\rightarrow$ virtuosidade] ou [gênero $\rightarrow$ conformidade], não chegam a ser significantes no todo, mas se confirmam numa ou noutra região, e por isso são mantidas na figura.

\section{FIGURA 3}

\section{RELAÇÕES SIGNIFICANTES IDENTIFICADAS}

NO MODELO ESTRUTURAL

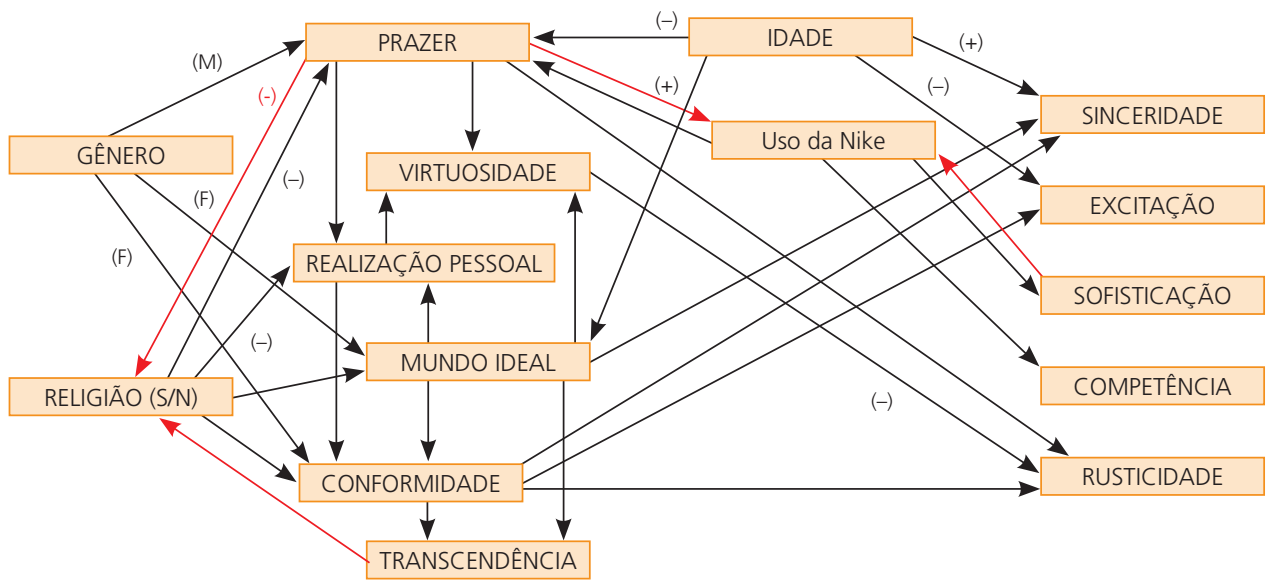

Fonte: Elaborada pelos autores. 
As relações não significantes foram excluídas da figura para facilitar a sua interpretação. A Tabela 4 apresenta os coeficientes das relações significantes para a amostra inteira (GMSNE), assim como as cargas padronizadas da análise multigrupo das subculturas gaúcha (G), mineira (M), sulista não gaúcha (S) e nordestina (NE).

\section{DISCUSSÃO}

O resultado confirma que a prática religiosa influencia positivamente os valores do idealismo e da conformidade, e negativamente o interesse pela realização pessoal. A busca pelo prazer e pela excitação interage (reforça e é reforçada) negativamente com a prática religiosa. E a transcendência, que depende apenas indiretamente da religiosidade, influencia direta e significativamente esta última. Dessa forma, é possível dizer que os indivíduos que participam de algum grupo ou atividade religiosa são significativamente mais idealistas e cumpridores das normas do sistema, e menos interessados na autorrealização e no prazer individual. Paralelamente, os valores da transcendência estimulam e os do prazer e da excitação afastam os indivíduos da prática religiosa. Confirma-se assim a interação entre os valores e a prática religiosa, mas não se confirma a influência desta última no uso ou não uso de uma marca simbólica (a Nike), nem na forma como os respondentes a percebem. Resta, assim, parcialmente confirmada a hipótese H-I.

TABELA 4

RELAÇÕES SIGNIFICANTES IDENTIFICADAS NO MODELO ESTRUTURAL, POR SUBCULTURAS

\begin{tabular}{lllllllllllll}
\hline ANTECEDENTE & CONSEQUENTE & GMSNE & $P$ & G. & $P$ & M. & $P$ & S. & $P$ & NE. & $P$ \\
\hline Conformidade & Transcendência & 0,57 & $* *$ & 0,63 & $* *$ & 0,67 & $* *$ & 0,31 & $* *$ & 0,39 & $* *$ \\
\hline Mundo ideal & Conformidade & 0,27 & $* *$ & 0,25 & $* *$ & - & - & 0,39 & $* *$ & - & - \\
\hline Mundo ideal & Realiz. pessoal & 0,35 & $* *$ & 0,23 & $* *$ & 0,72 & $* *$ & 0,38 & $* *$ & 0,35 & $* *$ \\
\hline Mundo ideal & Transcendência & 0,19 & $* *$ & 0,14 & $* *$ & - & - & 0,76 & $* *$ & 0,40 & $* *$ \\
\hline Mundo ideal & Virtuosidade & - & - & - & - & 0,38 & $* *$ & - & - & - & - \\
\hline Prazer & Realiz. pessoal & 0,29 & $* *$ & 0,25 & $* *$ & 0,45 & $* *$ & 0,38 & $* *$ & 0,19 & $* *$ \\
\hline Prazer & Virtuosidade & 0,17 & $* *$ & 0,21 & $* *$ & 0,36 & $* *$ & - & - & 0,26 & $* *$ \\
\hline
\end{tabular}




\section{TABELA 4 (CONTINUAÇÃo)}

\begin{tabular}{|c|c|c|c|c|c|c|c|c|c|c|c|}
\hline & $\begin{array}{l}\text { EAÇŐES SI } \\
\text { MODELO E }\end{array}$ & $\begin{array}{l}\text { GNIF } \\
\text { TRUT' }\end{array}$ & I J & $\begin{array}{l}\text { TTES } \\
\mathrm{AL}, \mathrm{P}\end{array}$ & $\begin{array}{l}\mathrm{DE} \\
\mathrm{R}\end{array}$ & UBC & & TUR & $\mathrm{S}$ & & \\
\hline ANTECEDENTE & CONSEQUENTE & GMSNE & $P$ & G. & P & M. & $P$ & S. & $P$ & NE. & $P$ \\
\hline Realiz. pessoal & Conformidade & 0,33 & ** & 0,23 & $\star \star$ & 0,78 & ** & - & - & 0,44 & ** \\
\hline Realiz. pessoal & Virtuosidade & 0,24 & ** & 0,17 & $\star *$ & - & - & - & - & 0,47 & ** \\
\hline Idade & Mundo ideal & 0,01 & ** & 0,01 & $\star \star$ & - & - & 0,02 & $\star \star$ & - & - \\
\hline Idade & Prazer & $-0,01$ & ** & $-0,02$ & $* *$ & - & - & - & - & - & - \\
\hline Religião & Conformidade & 0,18 & ** & - & - & 0,65 & ** & - & - & - & - \\
\hline Religião & Mundo ideal & 0,26 & ** & 0,23 & $\star *$ & 0,92 & ** & - & - & - & - \\
\hline Religião & Prazer & $-0,44$ & ** & $-0,44$ & $\star \star$ & - & - & - & - & - & - \\
\hline Religião & Realiz. pessoal & - & - & - & - & $-0,72$ & ** & - & - & - & - \\
\hline Sexo & Conformidade & - & - & - & - & - & - & 0,49 & ** & - & - \\
\hline Sexo & Mundo ideal & 0,33 & $\star \star$ & 0,28 & $\star \star$ & - & - & 0,54 & ** & 0,44 & ** \\
\hline Sexo & Prazer & $-0,24$ & ** & $-0,34$ & $\star *$ & - & - & - & - & - & - \\
\hline Uso & Prazer & 0,31 & ** & 0,35 & $* *$ & - & - & - & - & - & - \\
\hline Conformidade & Excitação & 0,12 & ** & 0,13 & $\star *$ & 0,26 & ** & - & - & - & - \\
\hline Conformidade & Rusticidade & 0,12 & $\star \star$ & 0,11 & $\star \star$ & 0,30 & ** & - & - & - & - \\
\hline Conformidade & Sinceridade & 0,11 & $\star *$ & - & - & - & - & - & - & 0,31 & ** \\
\hline Prazer & Rusticidade & 0,10 & ** & 0,09 & ** & - & - & - & - & 0,22 & ** \\
\hline Mundo ideal & Sinceridade & - & - & - & - & - & - & - & - & $-0,21$ & ** \\
\hline Virtuosidade & Rusticidade & $-0,12$ & ** & $-0,11$ & $* *$ & $-0,13$ & * & - & - & $-0,18$ & ** \\
\hline Idade & Excitação & $-0,005$ & ** & $-0,005$ & * & - & - & - & - & $-0,015$ & ** \\
\hline Idade & Sinceridade & 0,01 & $\star *$ & 0,01 & $\star \star$ & - & - & 0,02 & $\star \star$ & 0,01 & ** \\
\hline Uso & Competência & - & - & - & - & - & - & $-0,11$ & $\star \star$ & - & - \\
\hline Uso & Sofisticação & 0,34 & $\star \star$ & 0,41 & $\star \star$ & - & - & 0,60 & $\star \star$ & - & - \\
\hline
\end{tabular}

Fonte: Elaborada pelos autores.

$* \mathrm{P}<0, \mathrm{IO}$.

*** $\mathrm{P}<0,05$.

$\mathrm{G}=$ gaúcho; $\mathrm{M}=$ mineiro; $\mathrm{S}=$ sulista; $\mathrm{NE}=$ nordestino. 
A hipótese $\mathrm{H}-2$ presume que a idade correlaciona-se positivamente com os valores relacionados à segurança, à tradição e à conformidade, e negativamente com a estimulação, o hedonismo e com os desafios da autorrealização. Embora com outros nomes, o trabalho identifica três fatores compostos por valores indicativos do conservadorismo, da capacidade de renúncia e do interesse pela estabilidade (mundo ideal, conformidade e transcendência). A influência positiva da idade sobre esses fatores - especialmente sobre o primeiro deles - corrobora a relação sugerida por Schwartz (2006). E o mesmo ocorre em relação aos fatores que sugerem predileção pela independência e pelos desafios (realização pessoal, virtuosidade e prazer), cuja importância tende a diminuir com a idade, o que também é compatível com a hipótese que fora concebida com base na teoria.

A hipótese H-3, de que o nível de escolaridade dos respondentes correlaciona-se positivamente com a autodeterminação e com a abertura às mudanças, e negativamente com o conservadorismo, não se confirma nem na amostra completa, nem no nível das subculturas.

O resultado confirma a hipótese $\mathrm{H}-4$ de que os brasileiros do sexo masculino são mais assertivos e ambiciosos e que as mulheres são mais conciliadoras e transcendentes. Conforme se vê na Figura 3, as mulheres tendem a ser mais idealistas, conformistas e, consequentemente, também mais transcendentes do que os homens; e estes, por sua vez, valorizam distintivamente o prazer e a excitação, e consequentemente também as virtudes pessoais e a autorrealização. Ressalve-se, contudo, que a relação gênero $\rightarrow$ conformidade confirma-se apenas na subcultura sulista (não gaúcha), mas não nas demais (Tabela 4).

A hipótese $\mathrm{H}-5 \mathrm{a}$, de que existem diferenças significativas nos valores dos brasileiros, conforme a subcultura regional com a qual se identificam, se confirma tanto pela existência de diferenças absolutas quanto pelas relações dos valores entre si. Conforme já foi discutido no item 8.I, existem diferenças significativas de médias em cinco dos seis grupos de valores que foram identificados no modelo de mensuração. E além das diferenças absolutas, também existem diferenças nas relações dos valores entre si, como é o caso, por exemplo, do idealismo $\rightarrow$ virtuosidade, que ocorre entre os mineiros, mas não entre os demais. A hipótese $\mathrm{H}-5 \mathrm{~b}$, de que a unidade cultural brasileira deve prevalecer sobre as diversas subculturas regionais, também se confirma. Conforme se vê na Tabela 4, em 2I, das 25 relações que envolvem valores, as relações significantes no nível do(s) segmento(s) também se confirmam na amostra inteira, mas a recíproca não é verdadeira. Ou seja: apenas quatro, das 25 relações confirmadas, são tipicamente regionais; em todas as demais o todo prevalece sobre as partes.

A hipótese H-6, de que os valores (terminais e instrumentais) modelam a percepção da marca, também se confirma. Conforme se vê na Tabela 4, os indivíduos mais conformistas são aqueles que reconhecem cargas distintivas de 
sinceridade e de excitação na Nike. E ao mesmo tempo, o reconhecimento de rusticidade é influenciado diretamente pelos valores do prazer e da conformidade, e inversamente pela importância que os indivíduos dão às virtudes pessoais. A sofisticação e a competência da marca dependem de outros construtos, mas não são influenciados pelos valores. A influência do idealismo no reconhecimento de sinceridade na marca parece ser um fenômeno tipicamente nordestino, já que não se confirma no todo.

O resultado confirma a função mediadora que tem a posse ou o uso de produto(s) da Nike no reconhecimento da competência e da sofisticação daquela marca, assim como a sua interação com os valores do prazer. Conforme se vê na Figura 3, a competência e a sofisticação da marca não são influenciadas diretamente pelos valores, mas sim pelo uso/não uso da marca. E como o uso da marca tem relações nos dois sentidos com os valores do prazer, confirma-se integralmente a hipótese H-7.

Assim, resumindo, pode-se dizer que:

a) Confirma-se a relação de duplo sentido entre religião e valores;

b) Não se confirma a influência da prática religiosa no uso ou na percepção da marca;

c) Confirma-se a influência da idade, do gênero e do uso de uma marca simbólica na formação/reforço dos valores pessoais;

d) Não se confirma a influência da escolaridade sobre os valores, na amostra;

e) Confirma-se a diferença de valores entre as diversas subculturas regionais brasileiras;

f) Confirma-se a influência dos valores na percepção e na propensão a usar ou a não usar uma marca simbólica, largamente conhecida.

\section{CONCLUSÃO}

Este trabalho confirma alguns postulados já suficientemente descritos na teoria e levanta novos insights sobre a relação dos valores pessoais com os demais elementos da cultura e destes com as marcas ou produtos. Confirma, entre outras coisas, a influência de algumas condições demográficas na formação ou no reforço dos valores e na avaliação de uma marca. E confirma também a existência de diferenças entre os diversos "brasis culturais", cuja compreensão é fundamental para a definição de estratégias de marketing.

A confirmação de que a prática religiosa influencia positivamente os valores do idealismo e da conformidade, e negativamente o interesse pela realização pessoal, é compatível com a teoria esposada por Roccas e Schwartz (I997). 
Segundo esses autores, a religião correlaciona-se positivamente com a tradição, a segurança, a conformidade e a benevolência, e negativamente com o hedonismo, a estimulação e a autodeterminação. Entretanto, não se confirma, na amostra, a influência direta da prática religiosa na avaliação da marca, conforme sugerem Michell e Al-Mossawi (I999).

As correlações entre os valores revelam a existência de três áreas de interesse, semelhantes àquelas que foram identificadas por Schwartz e Bilsky (I987) e Schwartz (I992): uma área de valores de interesse coletivo, uma área de valores de alcance tipicamente individual e uma área de interesses mistos, composta pelos valores da maturidade, aqui denominados de realização pessoal, que servem tanto aos interesses individuais quanto aos da família e do grupo de relações. Conforme foi apresentado na Figura 2, o resultado corrobora a existência de antagonismos entre os valores da autodeterminação e da conformidade restritiva, entre a realização pessoal e a segurança, e entre o prazer e a transcendência (pró-social).

O resultado também corrobora os achados de Lenartowicz e Roth (200I) quanto à aversão ao risco e à modéstia dos mineiros, e quanto à independência e ao arrojo dos gaúchos, e inova na identificação de algumas características de nordestinos e sulistas, dois grupos que não foram contemplados naquele trabalho. A análise multigrupo dos valores confirma a existência de diferenças absolutas e conceituais entre as diversas subculturas brasileiras. A identificação de diferenças estatisticamente significantes nos valores preponderantes nos diversos grupos confirma os achados de Muzzio e Castro (2008), segundo os quais alguns traços como os valores, as atitudes e os comportamentos variam entre os diversos brasis culturais, e reforça a convicção quanto à necessidade de os profissionais de marketing compreenderem as nuanças comportamentais dos habitantes das diversas regiões brasileiras.

Os nordestinos, por exemplo, por serem significativamente mais transcendentes e conformistas, e também menos interessados nas virtudes pessoais, são mais resignados que os outros grupos. Os mineiros e os gaúchos são os grupos que mais valorizam o prazer e a excitação, e os sulistas não gaúchos dão grande importância aos valores de alcance coletivo, como aqueles de alcance universal (paz e justiça), e a outros de alcance grupal, como o amor, a amizade e a harmonia. Os sulistas em geral são mais arrojados e abertos às mudanças que os mineiros e os nordestinos, na medida em que valorizam distintivamente as virtudes pessoais, como a independência, a coragem e a capacidade individual. E os mineiros, que relutam em reconhecer maior importância à maioria dos valores e que, ao mesmo tempo, subordinam fortemente o idealismo, a conformidade e a realização pessoal à prática religiosa, confirmam o tipo pacato e introspectivo descrito por Muzzio e Castro (2008). 
Algumas das relações entre os valores e destes com outros construtos abrangem a totalidade da amostra, e outras são específicas de algumas subculturas. Conforme foi apresentado na Tabela 4, a influência da conformidade na transcendência e do prazer na realização pessoal, por exemplo, se confirma em todos os grupos. Mas o mesmo não acontece com a influência dos valores do mundo ideal na conformidade, que é própria dos sulistas (gaúchos ou não gaúchos), e do mundo ideal nas virtudes pessoais, que parece ser uma característica própria dos mineiros.

A influência das variáveis demográficas nos valores também varia conforme os tipos regionais com os quais os respondentes se identificam. A influência da idade no idealismo, por exemplo, é própria das subculturas sulistas, mas não se confirma entre os mineiros e nordestinos. E o gênero, que contribui significativamente para a conformidade das sulistas (não gaúchas), não tem influência naqueles valores entre as mulheres de outras subculturas.

A religiosidade, por sua vez, produz diferentes efeitos nos valores de gaúchos e mineiros, mas não chega a influenciar os valores dos outros grupos estudados. Além de estimular o idealismo em ambas as subculturas, a prática religiosa influencia outros valores de gaúchos e mineiros: entre os gaúchos, ela diminui a importância dada ao prazer e à excitação e não interfere na realização pessoal; e entre os mineiros, ao contrário, ela não afeta a busca pelo prazer, mas reduz significativamente o interesse pela realização pessoal.

A influência dos valores na percepção da marca também não segue um padrão único em todas as regiões. Os nordestinos mais conformistas, por exemplo, tendem a reconhecer doses distintivas de sinceridade na marca, entretanto o mesmo não ocorre com os demais. Conforme se vê na Tabela 4, a conformidade, que torna os nordestinos mais complacentes em relação à sinceridade da marca, é a mesma que leva os gaúchos e os mineiros a reconhecer a Nike como marca rústica e excitante, mas não como marca honesta.

O trabalho avança no conhecimento de marketing em aspectos teóricos, metodológicos e gerenciais. Do ponto de vista teórico, o trabalho confirma alguns postulados referentes às diferenças entre as subculturas regionais brasileiras e contribui para o entendimento da hierarquia dos valores e das suas inter-relações, assim como das interfaces que os conectam a outros construtos. Avança, sobretudo, na compreensão do papel desempenhado pelos valores e por outros elementos culturais e demográficos, como filtros de percepção para avaliação de uma marca simbólica.

Do ponto de vista metodológico, o trabalho avança na utilização de estimadores robustos para análise fatorial confirmatória com dados não normais. Como o método da máxima verossimilhança (ML) é o estimador padrão da maioria dos pacotes que realizam análise fatorial confirmatória, ele tem sido largamente empregado em trabalhos de marketing, mesmo que os dados não sejam perfeita- 
mente normais. Porém, "a utilização de um método que parte do pressuposto da normalidade, em condições de não normalidade, pode inflacionar erros do Tipo I e levar à rejeição indevida de alguns modelos" (CURRAN; WEST; FINCH, I996, p. I6). E o mesmo pode ser dito em relação à estimação de modelos com variáveis categóricas ou dicotômicas, para os quais o ML não é adequado (MUTHÉN; MUTHÉN, 2007). Assim, ao utilizar estimadores ainda pouco usuais em pesquisas de marketing (MLM e WLSMV), o trabalho é inovador também neste campo.

Do ponto de vista gerencial, o trabalho contribui substancialmente para a definição de estratégias de marketing, particularmente aquelas relacionadas à segmentação e ao posicionamento de marcas no contexto brasileiro. Além de confirmar algumas diferenças já conhecidas, entre os valores de gaúchos e mineiros (LENARTOWICZ; ROTH, 200I), o trabalho também identifica alguns aspectos típicos das subculturas nordestina e sulista não gaúcha, que podem ser de grande utilidade para a elaboração de propostas de marketing voltadas às diversas regiões do Brasil. A descoberta de que alguns valores e algumas condições demográficas produzem diferentes efeitos na percepção da marca, conforme o tipo regional com o qual os respondentes se identificam, pode ser de grande utilidade para a formatação e comunicação de novas ofertas. A constatação de que a idade favorece o reconhecimento de sinceridade na Nike, por exemplo, pode ser de grande utilidade para a elaboração de estratégias voltadas ao sul ou ao nordeste do Brasil, mas dificilmente produzirá o mesmo efeito entre os mineiros. E o contrário também pode acontecer com a prática religiosa que influencia substancialmente os valores da conformidade dos mineiros, mas não tem efeito significativo entre os demais grupos.

$\mathrm{O}$ trabalho tem importantes limitações quanto à amostra que foi utilizada. A primeira limitação diz respeito à ausência de cariocas e paulistas, duas importantes subculturas utilizadas por Lenartowicz e Roth (200I) que aqui não chegaram sequer a ser analisadas. A ausência de representações de São Paulo e do Rio de Janeiro, além de outras importantes regiões do país, não diminui a importância dos achados, mas reduz substancialmente a abrangência e a capacidade de generalização dos resultados.

Outra limitação importante diz respeito à assimetria das subamostras, onde o predomínio numérico dos gaúchos sobre os demais segmentos é incontestável. Ainda que os grupos de mineiros, nordestinos e sulistas não gaúchos apresentassem tamanho suficiente $(\mathrm{n}>30)$ para a realização de análise multigrupo, não há como atribuir a estes a mesma representatividade dos gaúchos $(\mathrm{n}=200)$. Tais constatações sugerem a necessidade de novos estudos, seja para comparar os grupos aqui estudados com outros ausentes (por exemplo, paulistas, cariocas, capixabas, candangos, pantaneiros, amazonenses etc.), seja para a identificação de possíveis grupos intrarregionais (por exemplo, serranos, missioneiros, fronteiriços do sul etc.). 


\section{REFERÊENCIAS}

AAKER, J. L. Dimensions of brand personality. Journal of Marketing Research, v. 34, n. 3, I997.

AMYX, D.; BRISTOW, D.; SCHNEIDER, K. A cross-cultural comparison of consumer tendencies and subsequent communication implications. Marketing Management Journal, v. I4, n. 2, p. 43-54, 2004 .

ANDERSON, J. C.; GERBING, D. W. Structural equation modeling in practice: a review and recommended two-step approach. Psychological Bulletin, v. I03, n. 3, p. 4II-423, I988.

AUSTIN, J. R.; SIGUAW, J. A.; MATTILA, A. S. A re-examination of the generalizability of Aaker brand personality measurement framework. Journal of Strategic Marketing, v. II, n. 2, 2003.

BAUMGARTNER, H.; HOMBURG, C. Applications of structural equation modeling in marketing and consumer research: a review. International Journal of Research in Marketing, v. I3, p. I39-I6I, I996.

BELK, R. Materialism: trait aspects of living in a material world. Journal of Consumer Research, v. I2, p. 265-280, I985.

BRISTOW, D.; AMYX, D. A cross-cultural look at consumer values: a Navajo vs. Anglo comparison. Marketing Management Journal, v. II, n. I, p. I5-24, 200 I.

BRISTOW, D. N. Do you see what I see? The marketing lens model in an academic setting. Journal of Marketing for Higher Education, v. 8 n. 4, p. I-I6, I998.

BROWN, R. Social identity theory: past achievements, current problems and future challenges. European Journal of Social Psychology, v. 30, p. 745-778, 2000.

BROWN, T. A. Confirmatory factor analysis for applied research. New York: The Guilford Press, 2006. BRUNSWIK, E. The conceptual framework of psychology. International Encyclopedia of Unified Science, v. I, n. IO, p. I9-2I, I952.

CHANG, C. Self-congruency as a cue in different advertising-processing contexts. Communication Research, v. 29, n. 5, 2002.

CHERNATONY, L. de. From brand vision to brand evaluation. 2. ed. Burlington, MA: Elevier, 2006.

CHERNATONY, L. de; RILEY, F. D. The chasm between managers' and consumers' views of brands. Journal of Strategic Marketing, v. 5, I997.

CLARK, T. International marketing and national character: a review and proposal for an integrative theory. Journal of Marketing, p. 66-79, I990.

CLAWSON, C. J; VINSON D. E. Human values: a historical and interdisciplinary analysis, Advances in Consumer Research, v. 5, n. I, I978.

COPELAND, M. T. Principles of merchandising. Chicago, New York: A. W. Shaw Company, I924. COSTELLO, A. B.; OSBORNE, J. W. Best practices in exploratory factor analysis: four recommendations for getting the most from your analysis. Practical Assessment Research \& Evaluation, v. Io, n. 7,2005 .

CURRAN, P. J.; WEST, S. G.; FINCH, J. F. The robustness of test statistics to nonnormality and specification error in confirmatory factor analysis. Psychological Methods, v. I, n. I, p. I6-29, I996. DA MATA, R. Nação e região: em torno do significado cultural e da permanente dualidade brasileira. In: SCHLEE, A. G.; SCHÜLER, F. L.; BORDINI, M. G. Cultura e identidade regional. Porto Alegre: Edipucrs, 2003. IO9 p.

DASGUPTA, R. Human values in management. Journal of Human Values, v. 3, n. 2, I997. 
FOURNIER, S. Consumers and their brands: developing relationship theory in consumer research. The Journal of Consumer Research, v. 24, n. 4, 1998.

GOUVEIA, V. V. et al. A estrutura e o conteúdo universais dos valores humanos: análise fatorial confirmatória da tipologia de Schwartz. Estudos de Psicologia, v. 6, n. 2, p. I33-I42, 200 I.

GUTMAN, J. A. Means-end chain model based on consumer categorization processes. Journal of Marketing, v. 46, n. 2, 1982.

HAIR JUNIOR, J. F. et al. Multivariate data analysis. 5. ed. Upper Saddle River: Prentice-Hall, I998. $730 \mathrm{p}$.

HILAL, A. V. G. Brazilian national culture, organizational culture and cultural agreement: findings from a multinational company. International Journal of Cross Cultural Management, v. 6, v. 2, p. I39I67, 2006.

HOFSTEDE, G. Culture's consequences. 2. ed. Thousand Oaks, CA: Sage Publications, 200I.

KAHLE, L. R.; BEATTY, S. E.; HOMER, P. Alternative measurement approaches to consumer values: the List list of Values values (LOV) and Values values and Life life Style style (VALS). Journal of Consumer Research, n. I3, I986.

KAHLE, L. R.; KENNEDY, P. Using the list of values LOV to understand consumers. The Journal of Services Marketing, v. 2, n. 4, I988.

KAMAKURA, W.; MAZZON, J. A. Value segmentation: a model for the measurement of value and value systems. Journal of Consumer Research, v. I8, I991.

KAMAKURA, W.; NOVAK T. P. Value-system segmentation: exploring the meaning of LOV. Journal of Consumer Research, v. I9, I992.

KLINE, R.B. Principles and practice of structural equation modeling. New York: Guilford Press. I998. $366 \mathrm{p}$.

LENARTOWICZ, T.; ROTH, T. A framework for culture assessment. Journal of International Business Studies, v. 30, n. 4, I999.

Does subculture within a country matter? A cross-cultural study of motivational domains and business performance in Brazil. Journal of International Business Studies, v. 32, n. 2, $200 \mathrm{I}$.

LUNA, D.; GUPTA, S. F. An integrative framework for cross-cultural consumer behavior. International Marketing Review, v. I8, n. I, 200I.

MACCALLUM, R. C.; AUSTIN, J. T. Applications of structural equation modeling in psychological research. Annual Review of Psychology, v. 5I, p. 20I-226, 2000.

MCCARTY, J. A.; SHRUM, L. J. The measurement of personal values in survey research. Public Opinion Quarterly, v. 64, 2000.

MCCRACKEN, G. Culture and consumption: a theoretical account of the structure of the cultural meaning of consumer goods. Journal of Consumer Research, v. I3, I986.

MICHELL, P.; AL-MOSSAWI, M. Religious commitment related to message contentiousness. International Journal of Advertising, v. I8, n. 4, p. 427-443, I999.

MUTHÉN, L. K.; MUTHÉN, B. O. MPlus: statistical analysis with latent variables - User's guide. Los Angeles (CA): Muthén \& Muthén, 2007.

MUZZIO, H.; CASTRO, D. J. Quantos somos nós? Uma reflexão sobre os brasis culturais. In: ENCONTRO DE ESTUDOS ORGANIZACIONAIS DA ANPAD, 5. 2008, Belo Horizonte. Anais... Belo Horizonte: Anpad, 2008.

NIQUE, W. M.; ESPINOZA, F.; SILVA, M. M. Análise da estrutura de valores pessoais: um estudo exploratório. In: ASSEMBLEIA ANUAL DO CLADEA, 2003, Lima. Anais... Lima: Cladea, 2003. 
NOVAK, T.; MACEVOY, B. Comparing alternative segmentation schemes: the list of values (LOV) and value and life stiles (VALS). Journal of Consumer Research, v.I7, n.I, I990.

OVERBY, J. W.; GARDIAL, S. F.; WOODRUFF, R. B. French versus American consumers' attachment of value to a product in a common consumption context: a cross-national comparison. Journal of the Academy of Marketing Science, v. 32, n. 4, 2004.

PITTS, R. E.; WOODSIDE, A. G. Personal values influences on consumer product class and brand preferences. The Journal of Social Psychology, v. II9, I983.

REYNOLDS, T. J.; GUTMAN, J. Laddering: extending the repertory grid methodology to construct attribute-consequence-value hierarchies. Journal of Advertising Research, v. 34, I994.

Advertising is image management. In: REYNOLDS, T. J.; OLSON, J. C. Understanding consumer decision making: the means-end approach to marketing and advertising strategy. New York: Lawrence Erlbaum, 200I. 472 p.

RIBEIRO, D. O povo brasileiro: a formação e o sentido do Brasil. São Paulo: Companhia das Letras, I995. $467 \mathrm{p}$.

ROCCAS, S.; SCHWARTZ, S. H. Church-State relations and the association of religiosity with values: A study of Catholics in six countries. Cross-Cultural Research, v. 3I, p. 356-375, Jan. I997.

ROKEACH, M. Beliefs, attitudes and values: a theory of organization and change. Hoboken, NJ: Jossey-Bass, I968.

. The nature of human values. New York: The Free Press, I973.

SCHWARTZ, S. H. Universal in the context and structure of values: theoretical advances and empirical tests in 20 countries. In: ZANNA, M. (Org.). Advances in experimental social psychology. Orlando: Academic Press, I992. v. 25, p. I-65.

Les valeurs de base de la personne: théorie, mesures et applications. Revue Française de Sociologie, v. 42, p. 249-288, 2006.

SCHWARTZ, S. H.; BILSKY, W. Toward a universal psychological structure of human values. Journal of Personality and Social Psychology, v. 53, I987.

SCHWARTZ, S. H.; RUBEL, T. Sex differences in value priorities: cross-cultural and multimethod studies. Journal of Personality and Social Psychology, v. 89, n. 6, p.Iого-Іо28, 2005.

SCHWARTZ, S. H.; SAVIG, L. Identifying culture-specifics in the content and structure of values. Journal of Cross-Cultural Psychology, v. 26, I995.

SPECK, S. K. S.; ROY, A. The interrelationships between television viewing, values and perceived well-being: a global perspective. Journal of International Business Studies, v. 39, p. II97-I219, 2008. TEIXEIRA, M. L. M.; DOMENICO, S. M. R. Gestores brasileiros e portugueses: estrutura única de valores de sentido de vida? Comportamento Organizacional e Gestão, v. I4, n. I, p. 45-64, 2008.

TEIXEIRA, M. L. M. et al. Sentidos de vida: um estudo transcultural entre gestores brasileiros e portugueses. Organizações \& Sociedade, v. I3, n. 38, p. 15-30, 2006.

TURNER, J. C. Social comparison and social identity: some prospect for intergroup behaviour. European Journal of Social Psychology, v. 5, n. I, p. 5-34, I975.

VALETTE-FLORENCE, P.; RAPACCHI, B. Improvements in means-end chain analysis using graph theory and correspondence analysis. Journal of Advertising Research, v. 3I, n. I6, I99I.

VINSON, D. E.; SCOTT, J. E.; LAMONT, L. M. The role of personal values in marketing and consumer behaviour. Journal of Marketing, p. 44-50, Apr. I977.

VRIENS, M.; HOFSTEDE, F. Linking attributes, benefits, and consumers values. Marketing Research, v. I2, n. 3, 2000. 